\title{
Assessment of the Use of Nanofluids in Spacecraft Active Thermal Control Systems
}

Eugene K. Ungar

NASA/Johnson Space Center

\section{$\underline{\text { Abstract }}$}

The addition of metallic nanoparticles to a base heat transfer fluid can dramatically increase its thermal conductivity. These nanofluids have been shown to have advantages in some heat transport systems. Their enhanced properties can allow lower system volumetric flow rates and can reduce the required pumping power. Nanofluids have been suggested for use as working fluids for spacecraft Active Thermal Control Systems (ATCSs). However, there are no studies showing the end-to-end effect of nanofluids on the design and performance of spacecraft ATCSs.

In the present work, a parametric study is performed to assess the use of nanofluids in a spacecraft ATCSs. The design parameters of the current Orion capsule and the tabulated thermophysical properties of nanofluids are used to assess the possible benefits of nanofluids and how their incorporation affects the overall design of a spacecraft ATCS. The study shows that the unique system and component-level design parameters of spacecraft ATCSs render them best suited for pure working fluids. The addition of nanoparticles to typical spacecraft thermal control working fluids actually results in an increase in the system mass and required pumping power. 


\title{
Assessment of the Use of Nanofluids in Spacecraft Active Thermal Control Systems
}

\author{
Eugene K. Ungar ${ }^{1}$ and Lisa R. Erickson ${ }^{2}$ \\ NASA/Johnson Space Center, Houston, TX, Zip 77058
}

\begin{abstract}
The addition of metallic nanoparticles to a base heat transfer fluid can substantially increase its thermal conductivity. These nanofluids have been shown to have advantages in some heat transport systems. Their thermal properties allow the system volumetric flow rate to be reduced, thus reducing the required pumping power. Nanofluids have been suggested as working fluids in spacecraft Active Thermal Control Systems (ATCSs). However, spacecraft ATCSs are unique in that they have stringent temperature control requirements and use specialized heat transfer devices. In the present work, a parametric study was performed to assess the use of nanofluids in spacecraft ATCSs. The tabulated thermophysical properties of various nanofluids, the design requirements of NASA's Orion ATCS and the performance parameters of its key heat transfer components were used to assess the effects of the incorporation of nanofluids. The study shows that the unique system and component-level design parameters of spacecraft ATCSs do not lend themselves to the use of nanofluids. The addition of nanoparticles to typical spacecraft internal flow loop working fluids actually results in an increase in either the system mass or the required pumping power, the opposite of the hoped-for effect. The intermediate results obtained in the study also suggest that that the addition of nanoparticles to an external ATCS loop is not likely to result in a significant overall system benefit.
\end{abstract}

\section{Nomenclature}

$=$ area

$=$ constant

$=$ specific heat

$=$ tubing inner diameter

$=$ Darcy-Weisbach friction factor

$=$ convective coefficient

$=$ fluid thermal conductivity

$=$ tubing length

$=$ head loss coefficient

$=$ mass flow rate

$=$ Nusselt number

$=$ Prandtl number

$=$ system heat load

$=$ Reynolds number

$\mathrm{T}=$ temperature

UA $=$ heat exchanger heat transfer coefficient

$\mathrm{V} \quad=$ average flow velocity

$\Delta \mathrm{p} \quad=$ pressure difference

$\Delta \mathrm{T} \quad=$ temperature difference

$\varepsilon=$ radiator emissivity

$\eta \quad=\quad$ radiator fin efficiency

$\mu \quad=$ dynamic viscosity

\footnotetext{
${ }^{1}$ Senior Thermal and Fluids Analyst, Crew and Thermal Systems Division, EC2.

${ }^{2}$ Cooperative Education Student, Crew and Thermal Systems Division, EC2.
} 


$$
\begin{array}{ll}
\rho & =\text { density } \\
\sigma & =\text { Stefan-Boltzmann constant }
\end{array}
$$

\begin{tabular}{ll}
\multicolumn{2}{c}{ subscripts } \\
avg. & $=$ average \\
bf & $=$ base fluid $-60 / 40$ ethylene glycol/water \\
comp.,fittings, CVs & $=$ in components, fittings, and control valves \\
HFE 7000 & $=$ HFE 7000 coolant \\
$\mathrm{H} / \mathrm{X}$ & $=$ in heat exchanger \\
$\mathrm{ht}$ & $=$ heat transfer \\
$\mathrm{L}$ & $=$ laminar \\
$\mathrm{nf}$ & $=$ nanofluid - base fluid with added nanoparticles \\
tubing & $=$ in tubing \\
$\mathrm{T}$ & $=$ turbulent \\
$\Delta p$ & $=$ pressure difference \\
$\infty$ & $=$ radiator sink
\end{tabular}

\section{Introduction}

A CTIVE Thermal Control Systems (ATCSs) are used on spacecraft to remove waste heat from electronics and habitable volumes. They can use one loop or two loops in series. In single loop systems, a single pumped loop collects waste heat from the crew cabin and spacecraft components and rejects it to the environment. Dual loop systems use separate loops inside and outside of the crew cabin. The two loops are connected by an interloop heat exchanger.

Normally redundant ATCSs are used to provide fault tolerance. That is, a spacecraft using a single loop system would have multiple parallel loops. A spacecraft using a two loop system would have multiple separate pairs of internal and external loops. The discussion in the present work assesses a single set of redundant loops.

ATCSs on US human spacecraft have historically used commonly available working fluids as listed in Table 1. The table lists the fluid used in the internal pumped loop and the fluid used in the external pumped loop - where applicable*.

Early in the US human space program, working fluid toxicity was not an overriding concern and single loop systems used a fluid with good thermal performance and a low freezing point. With the advent of the Space Shuttle, lack of toxicity became a requirement for any working fluid used inside the spacecraft cabin. This led to the use of two loop systems where a non-toxic high freezing point fluid loop flows through the crew cabin. An interloop heat exchanger transfers the spacecraft waste heat to an external loop containing a low freezing point fluid.

It has been suggested that adding nanoparticles to a spacecraft ATCS might increase its performance, decrease its mass, and reduce its pumping power ${ }^{1}$. However, there have been no end-to-end studies that investigate the effects of adding nanoparticles to spacecraft ATCSs. In the present work, a parametric assessment was performed. The tabulated thermophysical properties of various nanofluids, the design requirements of the current Orion ATCS and the performance parameters of its key heat transfer components were used to assess the effects of incorporating nanofluids. Because minimizing mass and power is the main goal of spacecraft design, the nanofluids' benefits were assessed based on their effect on the overall mass and required pump power of the ATCS.

Table 1. Human Spacecraft Active Thermal Control System Working Fluids

\begin{tabular}{|c|c|c|}
\hline Spacecraft & Internal Pumped Loop & External Pumped Loop \\
\hline Gemini & \multicolumn{2}{|c|}{ silicone ester oil (single loop) } \\
\hline Apollo Command Module & \multicolumn{2}{|c|}{ water/ethylene glycol mixture (single loop) } \\
\hline Apollo Lunar Module & \multicolumn{2}{|c|}{ water/ethylene glycol mixture (single loop) } \\
\hline Skylab & \multicolumn{2}{|c|}{ silicone ester oil (single loop) } \\
\hline Space Shuttle & water & Freon-21 \\
\hline International Space Station & inhibited water & anhydrous ammonia \\
\hline Orion & $\begin{array}{c}\text { water/Dowfrost HD (inhibited } \\
\text { propylene glycol) mixture }\end{array}$ \\
\hline
\end{tabular}

* The Mercury spacecraft used air cooling only, so it is not listed. 


\section{Overview of Orion's ATCS}

Orion's ATCS is a two loop system as shown in Figure 1. The loop that circulates through the pressurized volume contains a 50/50 mixture of water and Dowfrost HD inhibited propylene glycol. The external loop uses HFE 7000. A ruffled fin compact heat exchanger connects the two loops.

The water/Dowfrost HD fluid loop sequentially cools the cabin air heat exchanger, internal coldplates, and external coldplates. The coldplates cool the spacecraft avionics and batteries. Coolant is provided to the cabin air heat exchanger at a setpoint temperature of $281.4 \mathrm{~K}\left(47^{\circ} \mathrm{F}\right)-\mathrm{a}$ temperature derived from the cabin humidity control requirements. This setpoint is maintained using an internal bypass control. Owing to the low battery coldplate heat flux, the fluid exit temperature design limit is equivalent to the maximum allowable battery baseplate temperature of $303.2 \mathrm{~K}$ $\left(86^{\circ} \mathrm{F}\right)$.

The water/Dowfrost HD transfers its heat to the external fluid loop at the interloop heat exchanger. The external fluid loop rejects the waste heat to the radiator array. A regenerator bypass ${ }^{2}$ is used to maintain the desired HFE 7000 return temperature over the range of vehicle heat loads and radiator environments. In the event that the radiator capacity is exceeded, an evaporative heat sink vents water or ammonia to provide supplemental cooling.

For the purposes of the present study, the spacecraft design point is considered. This is the condition where the required cooling needs are only just met with:

- the internal bypass leg closed,

- the regenerator fully bypassed,

- and the evaporator inactive.

\section{Study Methodology}

To assess the benefits of using nanofluids as spacecraft ATCS working fluids, a detailed parametric analysis was performed using the Orion internal ${ }^{\dagger}$ system as a baseline. The literature contains thermophysical property data for nanofluids composed of metallic nanoparticles added to a water/ethylene glycol mixture, so a conceptual design of an Orion internal loop using $60 \%$ ethylene glycol and $40 \%$ water was used as the baseline ${ }^{\ddagger}$. The performance of the nanofluids was assessed in two ways: 1) by calculating the change in system mass while maintaining the same pumping power and 2) by calculating the change in pump power while maintaining the same system mass.

\footnotetext{
${ }^{\dagger}$ Because there are no available property databases for HFE 7000-based nanofluids, the external loop was not addressed specifically in this study. However, the intermediate results for the internal loop study point toward a likely result for the external loop, as will be discussed in the Results section.

* The properties for ethylene glycol and water mixtures will differ from those of the inhibited propylene glycol and water mixture used by Orion, but the overall trends with nanoparticles are expected to be similar owing to the similar nature of the base fluids.
} 
Table 2. Properties of 60:40 Water/Ethylene Glycol with Nanoparticles at 298K

\begin{tabular}{|cccccccc|}
\hline Nanoparticle & $\begin{array}{c}\text { Volumetric } \\
\text { Concentration }\end{array}$ & $\begin{array}{c}\text { Density } \\
\mathrm{kg} / \mathrm{m}^{3}\end{array}$ & $\begin{array}{c}\text { Viscosity } \\
\mathrm{kg} /(\mathrm{m} \mathrm{s})\end{array}$ & $\begin{array}{c}\text { Specific } \\
\text { Heat } \\
\mathrm{J} /(\mathrm{kg} \mathrm{K})\end{array}$ & $\begin{array}{c}\text { Thermal } \\
\text { Conductivity } \\
\mathrm{W} /(\mathrm{m} \mathrm{K})\end{array}$ & $\begin{array}{c}\text { Prandtl } \\
\text { No. }\end{array}$ & $\begin{array}{c}\text { Volumetric } \\
\text { Specific } \\
\text { Heat } \\
\mathrm{kJ} /\left(\mathrm{m}^{3} \mathrm{~K}\right)\end{array}$ \\
\hline none & 0.00 & 1084 & 0.00423 & 3148 & 0.3729 & 35.75 & 3412 \\
\hline $\begin{array}{c}\text { Aluminum } \\
\text { Oxide } \\
\left(\mathrm{Al}_{2} \mathrm{O}_{3}\right)\end{array}$ & 0.01 & 1109 & 0.00474 & 3071 & 0.4104 & 35.45 & 3405 \\
& 0.02 & 1134 & 0.00539 & 2997 & 0.4203 & 38.45 & 3399 \\
& 0.03 & 1159 & 0.00614 & 2926 & 0.4311 & 41.67 & 3392 \\
& 0.04 & 1184 & 0.00699 & 2859 & 0.4423 & 45.17 & 3385 \\
\hline $\begin{array}{c}\text { Copper } \\
\text { Oxide }(\mathrm{CuO})\end{array}$ & 0.05 & 1209 & 0.00796 & 2794 & 0.4538 & 48.97 & 3379 \\
& 0.06 & 1235 & 0.00906 & 2731 & 0.4657 & 53.12 & 3372 \\
& 0.01 & 1138 & 0.00489 & 2999 & 0.4123 & 35.59 & 3412 \\
& 0.02 & 1192 & 0.00615 & 2863 & 0.4243 & 41.49 & 3413 \\
& 0.03 & 1246 & 0.00773 & 2739 & 0.4362 & 48.54 & 3413 \\
& 0.05 & 1300 & 0.00971 & 2625 & 0.4480 & 56.92 & 3414 \\
& 0.06 & 1354 & 0.01224 & 2521 & 0.4600 & 66.90 & 3414 \\
& & 1409 & 0.01534 & 2424 & 0.4721 & 78.79 & 3415 \\
\hline
\end{tabular}

Aluminum oxide and copper oxide nanoparticles at concentrations ranging from 0 to $6 \%$ by volume were assessed. The fluid properties were taken at $298 \mathrm{~K}\left(76.7^{\circ} \mathrm{F}\right)$, a temperature where properties are available in the existing databases ${ }^{3,4}$, that is approximately equal to the average inner loop fluid temperatures. The properties for each nanofluid are shown in Table 2.

The baseline design was developed from the following Orion ATCS design requirements and component performance parameters:

- Loop heat load $=2.5 \mathrm{~kW}$ (for one of the two ATCS loop pairs)

- Internal loop setpoint temperature of $281.5 \mathrm{~K}\left(47^{\circ} \mathrm{F}\right)$

- Maximum internal loop temperature of $303.2 \mathrm{~K}\left(86^{\circ} \mathrm{F}\right)$.

- Internal loop transport length of $50 \mathrm{~m}(162.5 \mathrm{ft})$

- $\quad 0.035$ in wall titanium tubing, which was assumed to be available in any needed diameter - not just in stock tube sizes. The tubing density was taken as $4488 \mathrm{~kg} / \mathrm{m}^{3}\left(280.2 \mathrm{lbm} / \mathrm{ft}^{3}\right)$.

- The total Orion internal loop pressure drop of $172 \mathrm{kPa}(25 \mathrm{psid})$ was apportioned as:

- $30 \%$ from tubing friction,

- $60 \%$ from components (other than the heat exchanger), valves, and fittings

- $10 \%$ from the interloop heat exchanger

- The product of mass flow rate and specific heat is the same in the internal and external loops

- The temperature difference across the counterflow interloop heat exchanger at full load is $3.9 \mathrm{~K}\left(7^{\circ} \mathrm{F}\right)$ and is uniform

- $1 / 5$ th of the temperature drop is across the water/Dowfrost HD side

- $4 / 5$ th of the temperature drop is across the HFE 7000 side

- The radiator parameters were

- $\quad$ Sink temperature of $233.15 \mathrm{~K}\left(-40^{\circ} \mathrm{F}\right)$

- $\quad$ Surface emissivity of 0.9

- $\quad$ Fin efficiency of 0.95

- Includes the minor effect of the internal film heat transfer resistance

- Specific mass was based on the space shuttle value of $5.85 \mathrm{~kg} / \mathrm{m}^{2}\left(1.20 \mathrm{lbm} / \mathrm{ft}^{2}\right)$ - the Orion radiator design details had not been finalized at the time of the present work. 
The study baseline design for the 60/40 mixture of ethylene glycol (EG) and water yielded:

- Mass flow rate of $0.0366 \mathrm{~kg} / \mathrm{s}(290 \mathrm{lbm} / \mathrm{hr})$ in the water/EG 1 loop $^{\S}$

- Volumetric flow rate of $3.38 \times 10-5 \mathrm{~m}^{3} / \mathrm{s}\left(4.29 \mathrm{ft}^{3} / \mathrm{hr}\right)$

- Tubing internal diameter of $8.64 \mathrm{~mm}(0.34 \mathrm{in})$

- Radiator area of $12.94 \mathrm{~m}^{2}\left(139.285 \mathrm{ft}^{2}\right)$

- $\quad$ based on the average radiator fluid temperature.

The effects of nanofluids were assessed parametrically by calculating the change in tubing mass, fluid mass, accumulator mass, radiator mass, and pump power caused by the substitution of the nanofluid. The detailed study methodology and results are discussed next.

1. Constant Pump Power Method

The first method used in the study assessed the change in overall system mass given a constant pump power. Since the volumetric specific heat of the base fluid and nanofluids is the same within $1 \%$, the loop volumetric flow rate is taken to be the same for all the cases. Thus, constant pump power implies that the internal loop pressure drop does not change with the addition of nanoparticles.

The pressure drop, $\Delta \mathrm{p}$, through the system was calculated by summing the pressure drop through the tubing, components, fittings, and control valves, plus the heat exchanger:

$$
\Delta p=\Delta p_{\text {tubing }}+\Delta p_{\text {comp.,fittings } \& \text { CVs }}+\Delta p_{H / X}
$$

The tubing pressure drop is calculated using standard methods

$$
\Delta \mathrm{p}_{\text {tubing }}=\mathrm{f} \frac{1}{\mathrm{~d}} \frac{1}{2} \rho \mathrm{V}^{2}
$$

where $\mathrm{f}$ is the Darcy-Weisbach friction factor, 1 is the flow path length of $50 \mathrm{~m}(132.5 \mathrm{ft}), \mathrm{d}$ is the tube inner diameter, $\rho$ is the fluid density, and $\mathrm{V}$ is the average flow velocity.

The component, fitting, and control valve pressure drop is calculated using a constant head loss, L, which was taken from the base fluid calculation

$$
\Delta \mathrm{p}_{\text {comp.fittings \&CVs }}=\mathrm{L} \frac{1}{2} \rho V^{2}
$$

The heat exchanger pressure drop with the nanofluid, $\Delta \mathrm{p}_{\mathrm{nf}}$, was calculated based on the pressure drop with the base fluid, $\Delta \mathrm{p}_{\mathrm{bf}}$,

$$
\Delta \mathrm{p}_{\mathrm{nf}}=\frac{\Delta \mathrm{p}_{\mathrm{nf}}}{\Delta \mathrm{p}_{\mathrm{bf}}} \Delta \mathrm{p}_{\mathrm{bf}}
$$

The subscripts bf and $\mathrm{nf}$ refer to the base fluid and the nanofluid, respectively.

The ratio of heat exchanger pressure drops was calculated for both laminar and turbulent flows from compact ruffled fin heat exchanger performance data ${ }^{5}$. For turbulent flow, the Darcy-Weisbach friction factor is:

$$
f=c_{\Delta p, T} R e^{-0.442}
$$

and for laminar flow:

$$
\mathrm{f}=\frac{\mathrm{c}_{\Delta \mathrm{p}, \mathrm{L}}}{\operatorname{Re}}
$$

\footnotetext{
$\S$ The internal loop mass flow rate was calculated using $Q=\dot{m} c_{p} \Delta T$ where $\mathrm{Q}$ is the heat transferred across the interloop heat exchanger, $\dot{m}$ is the mass flow rate of fluid in the loop, $\mathrm{c}_{\mathrm{p}}$ is the specific heat of the fluid, and $\Delta \mathrm{T}$ is the temperature rise through the loop $\left(21.7^{\circ} \mathrm{C}\right.$ or $\left.39^{\circ} \mathrm{F}\right)$.
} 
where $R e$ is the Reynolds number of the fluid and $\mathrm{c}_{\Delta \mathrm{p}, \mathrm{T}}$ and $\mathrm{c}_{\Delta \mathrm{p}, \mathrm{L}}$ are pressure drop constants for turbulent and laminar flow, respectively. By using the ratio of the nanofluid and base fluid pressure drops, $\Delta \mathrm{p}_{\mathrm{nf}} / \Delta \mathrm{p}_{\mathrm{bf}}$, as the key variable, the heat exchanger characteristic diameter, flow velocity, and $\mathrm{c}_{\Delta \mathrm{p}, \mathrm{T}}$ and $\mathrm{c}_{\Delta \mathrm{p}, \mathrm{L}}$ cancel.

So, for turbulent flow:

$$
\frac{\Delta \mathrm{p}_{\mathrm{nf}}}{\Delta \mathrm{p}_{\mathrm{bf}}}=\left(\frac{\dot{\mathrm{m}}_{\mathrm{nf}} \mu_{\mathrm{bf}}}{\dot{\mathrm{m}}_{\mathrm{bf}} \mu_{\mathrm{nf}}}\right)^{-0.442} \frac{\rho_{\mathrm{bf}}}{\rho_{\mathrm{nf}}}\left(\frac{\dot{\mathrm{m}}_{\mathrm{nf}}}{\dot{\mathrm{m}}_{\mathrm{bf}}}\right)^{2}
$$

And for laminar flow:

$$
\frac{\Delta \mathrm{p}_{\mathrm{nf}}}{\Delta \mathrm{p}_{\mathrm{bf}}}=\left(\frac{\dot{\mathrm{m}}_{\mathrm{bf}} \mu_{\mathrm{nf}}}{\dot{\mathrm{m}}_{\mathrm{nf}} \mu_{\mathrm{bf}}}\right) \frac{\rho_{\mathrm{bf}}}{\rho_{\mathrm{nf}}}\left(\frac{\dot{\mathrm{m}}_{\mathrm{nf}}}{\dot{\mathrm{m}}_{\mathrm{bf}}}\right)^{2}
$$

where $\dot{m}$ is the mass flow rate and $\mu$ is the viscosity.

To size the tubing for a given nanofluid, the heat exchanger pressure drop was first calculated. The tube diameter was then adjusted to maintain the same overall pressure drop of $172.37 \mathrm{kPa}$ (25psi) with the same component, fitting, and control valve loss coefficient and flow length as the baseline system. Once the tube diameter was finalized and the new loop volume was known, the additional required accumulator volume and mass was calculated $^{* *}$.

The addition of the nanoparticles changes the performance of the interloop heat exchanger, changing the temperature of the external fluid loop, and changing the required radiator size. The change in heat exchanger performance caused by the nanofluids was calculated using a methodology similar to that used for the heat exchanger pressure drop.

The Nusselt number for the compact ruffled fin heat exchangers ${ }^{5}$ is:

$$
\mathrm{Nu}=\mathrm{c}_{\mathrm{ht}, \mathrm{T}} \operatorname{Re}^{0.595} \operatorname{Pr}^{1 / 3}
$$

for turbulent flow and

$$
\mathrm{Nu}=\mathrm{c}_{\mathrm{ht}, \mathrm{L}}
$$

and for laminar flow. Here $\operatorname{Pr}$ is the Prandtl Number of the fluid and $c_{h t, T}$ and $c_{h t, L}$ are heat transfer constants for turbulent and laminar flows, respectively.

The change in the heat exchanger convection coefficient is calculated from

$$
\frac{\mathrm{h}_{\mathrm{nf}}}{\mathrm{h}_{\mathrm{bf}}}=\frac{\mathrm{k}_{\mathrm{nf}}}{\mathrm{k}_{\mathrm{bf}}}\left(\frac{\dot{\mathrm{m}}_{\mathrm{nf}} \mu_{\mathrm{bf}}}{\dot{\mathrm{m}}_{\mathrm{bf}} \mu_{\mathrm{nf}}}\right)^{0.5952}\left(\frac{\operatorname{Pr}_{\mathrm{nf}}}{\operatorname{Pr}_{\mathrm{bf}}}\right)^{1 / 3}
$$

for turbulent flow and

$$
\frac{\mathrm{h}_{\mathrm{nf}}}{\mathrm{h}_{\mathrm{bf}}}=\frac{\mathrm{k}_{\mathrm{nf}}}{\mathrm{k}_{\mathrm{bf}}}
$$

for laminar flow. Here $k$ is the thermal conductivity of the fluid.

These convection coefficient ratios were used to calculate the change in heat exchanger performance. The overall heat exchanger heat transfer coefficient with the base fluid, $\mathrm{UA}_{\mathrm{H} / \mathrm{X}, \mathrm{bf}}$, is $642 \mathrm{~W} / \mathrm{K}\left(1218 \mathrm{BTU} / \mathrm{hr}^{\circ} \mathrm{F}\right)$ based on the Orion loop performance. $\mathrm{UA}_{\mathrm{H} / \mathrm{X}, \mathrm{bf}}$ can be expressed as the sum of the heat transfer on the internal loop side, $\mathrm{UA}_{\mathrm{bf}}$, and on the HFE 7000 side, $\mathrm{UA}_{\mathrm{HFE}} 7000$.

\footnotetext{
${ }^{* *}$ The required increase in accumulator volume was calculated by comparing the volumetric change of the nanofluid system to the baseline system from the sink temperature of $233.15 \mathrm{~K}\left(-40^{\circ} \mathrm{F}\right)$ to the average loop temperature of $218.43 \mathrm{~K}\left(66.5^{\circ} \mathrm{F}\right)$. The increase in accumulator volume resulted in additional liquid inventory mass plus accumulator mass. The additional accumulator mass was taken as equal to the product of the base fluid density and the accumulator volume change.
} 


$$
\mathrm{UA}_{\mathrm{H} / \mathrm{X}, \mathrm{bf}}=\frac{1}{\frac{1}{\mathrm{UA}_{\mathrm{bf}}}+\frac{1}{\mathrm{UA}_{\mathrm{HFE} 7000}}}
$$

Based on the study assumptions listed previously, the base fluid overall heat transfer coefficient is four times the HFE 7000 overall heat transfer coefficient, so $\mathrm{UA}_{\mathrm{bf}}=3216 \mathrm{~W} / \mathrm{K}\left(6093 \mathrm{BTU} / \mathrm{hr}^{\circ} \mathrm{F}\right)$, and $\mathrm{UA}_{\mathrm{HFE}} 7000=803 \mathrm{~W} / \mathrm{K}$ (1523 BTU/hro F).

The heat exchanger performance with the nanofluid, $\mathrm{UA}_{\mathrm{H} / \mathrm{X}, \mathrm{nf}}$, be calculated from

$$
\mathrm{UA}_{\mathrm{H} / \mathrm{X}, \mathrm{nf}}=\frac{1}{\left(\frac{\mathrm{h}_{\mathrm{bf}}}{\mathrm{h}_{\mathrm{nf}}}\right) \frac{1}{\mathrm{UA}_{\mathrm{bf}}}+\frac{1}{\mathrm{UA}_{\mathrm{HFE}} 7000}}
$$

This allows the nanofluid heat exchanger temperature difference, the average radiator fluid temperature, and the new required radiator area to be calculated.

The average HFE 7000 temperature, $T_{\text {HFE 7000,avg, }}$ is the internal loop average temperature less the heat exchanger temperature drop.

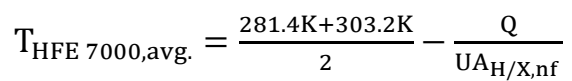

where $\mathrm{Q}$ is the system heat load of $2.5 \mathrm{~kW}$. The required radiator area, $\mathrm{A}_{\mathrm{rad}}$, is calculated from radiation principles

$$
A_{\text {rad }}=\frac{Q}{\varepsilon \eta \sigma\left(T_{H F E}^{4} 7000, \text { avg. }-T_{\infty}^{4}\right)}
$$

where $\varepsilon$ is the radiator emissivity, $\eta$ is radiator fin efficiency, $\sigma$ is the Stefan-Boltzman constant, and $T_{\infty}$ is the effective sink temperature.

The change in tube and accumulator size, required fluid volume, and radiator area was then used to find the overall change in the mass of the system caused by the addition of nanoparticles.

2. Constant System Mass Method

The second method assessed the change in required pump power for a nanofluid system with the same mass as the base fluid system. Here the same constitutive equations were used as in the constant pump power method, but changes in radiator mass were offset by changes in the internal loop mass (including the accumulator).

For a given nanofluid, the change in radiator performance from the constant pump power method was first used to calculate the change in radiator mass. This change in mass was then applied (with opposite sign) to the internal loop and used to calculate the new tubing diameter.

Since the volumetric flow rate was invariant throughout the analysis, the change in pump power is proportional to the change in internal loop pressure drop.

\section{Results}

A. Constant Pump Power

1. Interloop Heat Exchanger Performance

Adding nanoparticles did not always improve the performance of the innerloop heat exchanger. Figure 2 shows the change in the hot side convection coefficient with the addition of nanoparticles. The laminar flow heat transfer improves substantially with the addition of nanoparticles. For turbulent heat transfer, small amounts of nanoparticles improve the heat transfer, but larger amounts

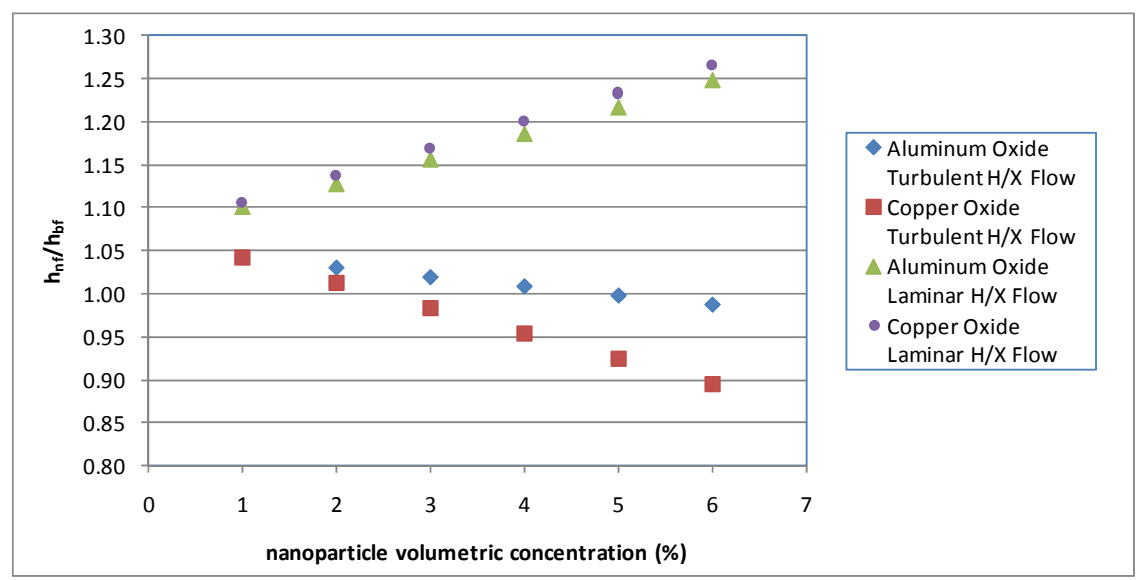

Figure 2. Heat Exchanger Hot Side Convection Coefficient - Constant Pump Power 
reduce it. The higher nanofluid viscosity decreases the turbulent Reynolds number and lowers the convection coefficient.

\section{Radiator Area}

While the most of the nanofluid combinations improved the performance of the interloop heat exchanger, the improvement occurred on the high performance internal loop side (which has only $1 / 5^{\text {th }}$ of the overall temperature drop). The overall effect on radiator area was therefore minor. Figure 3 shows the radiator area required to reject $2.5 \mathrm{~kW}$. The best performing nanofluid generated less than a $0.4 \%$ decrease in radiator area $\left(0.05 \mathrm{~m}^{2}\right.$ or $\left.0.4 \mathrm{ft}^{2}\right)$. 3. Radiator Mass

The addition of nanofluids resulted in only minor changes in radiator mass. Figure 4 shows the radiator mass corresponding to the radiator areas in Figure 3. The maximum savings was $0.3 \mathrm{~kg}$ $(0.66 \mathrm{lbm})$, less than $0.4 \%$ of the radiator mass.

\section{Tubing Diameter}

The addition of nanofluids uniformly resulted in larger tubing inner diameter to maintain the same overall loop pressure drop. The higher density and viscosity of the nanofluids required lower loop fluid velocities to meet the pressure drop targets. Figure 5 shows the tube inner diameters for a total loop pressure drop of $172.37 \mathrm{kPa}(25 \mathrm{psi})$. It shows that the tube diameter must be increased by as much as $30 \%$ to accommodate the nanofluid while maintaining the overall system pressure drop.

\section{Overall System Mass}

The overall change in system mass resulting from the addition of nanoparticles to the internal loop is shown in Figure 6. The additional mass resulting from the larger required tube diameter more than offsets the radiator mass savings. None of the nanofluids assessed for the constant pump power case resulted in a system mass savings.

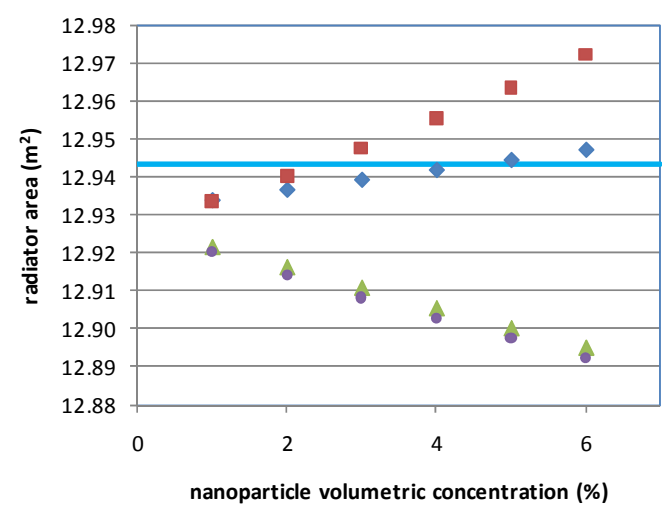

Aluminum Oxide Turbulent H/X Flow H/X Flow

Aluminum Oxide Laminar H/X Flow

- Copper Oxide Laminar H/X Flow

Base Fluid
- Copper Oxide Turbulent

\section{Figure 3. Radiator Area Required to Reject 2.5kW - Constant Pump Power}

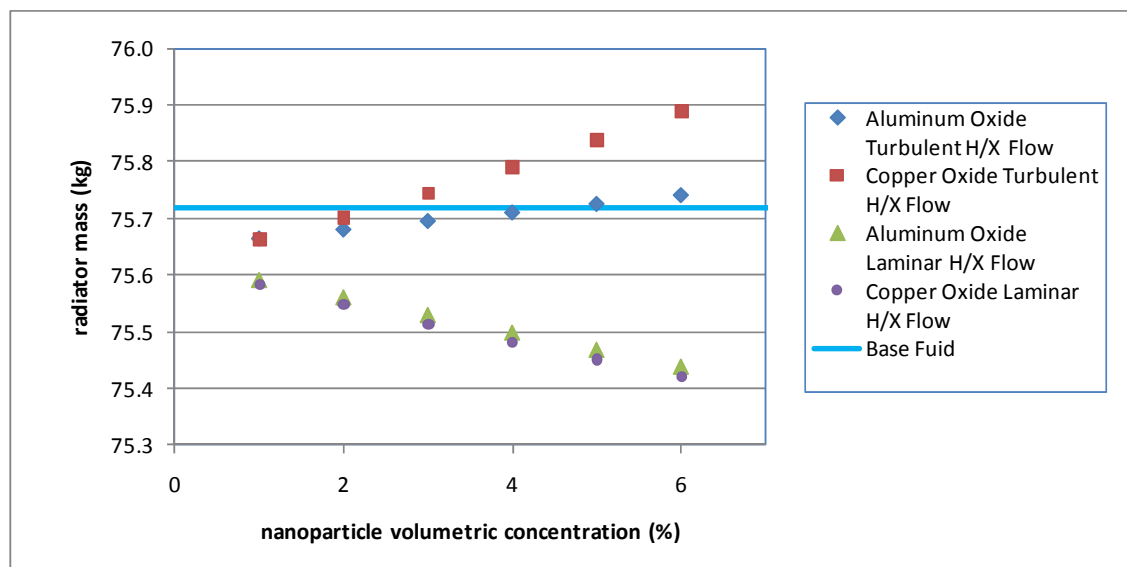

\section{Figure 4. Radiator Mass Comparison - Constant Pump Power}

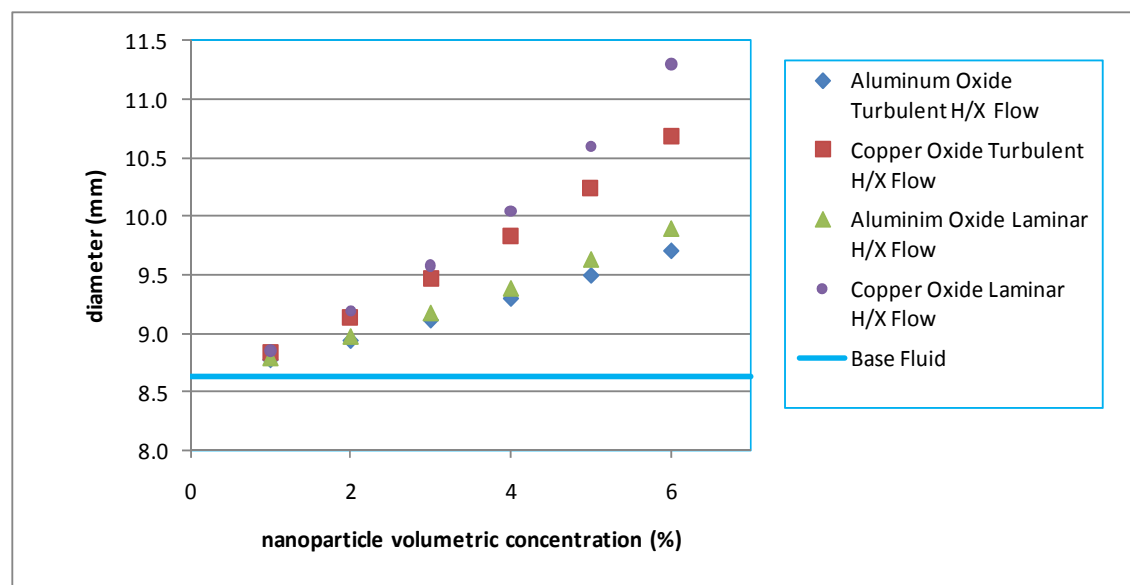

Figure 5. Tube Inner Diameter for Constant Pressure Drop - Constant Pump Power

American Institute of Aeronautics and Astronautics 


\section{B. Constant System Mass}

When the constant system mass analysis method was used, the higher density of the nanofluid almost always resulted in smaller diameter tubing for the internal loop. The tube inner diameters for a constant system mass are shown in Figure 7.

\section{Pump Power}

The smaller tube diameters and the increased pressure drop in the heat exchanger lead to a greater pressure drop in the internal loop. The nanofluids' higher density and viscosity plus the smaller tube diameter result in much higher pressure drop and associated pump power. The calculated increase in pump power is shown in Figure 8. All the nanofluid pump powers are higher than for the baseline system. The highest concentrations of nanoparticles result in between a 60 and $200 \%$ increase in the pump power for the constant mass system.

\section{Summary}

For both the constant power case and the constant mass case, the addition of nanoparticles to the internal thermal control loop did not result in a better system design. The rigid setpoint and maximum temperature requirements common to all spacecraft ATCSs do not allow a decrease in the system volumetric flow rate with the addition of nanoparticles. The increased pressured drop caused by the higher density and viscosity of the nanofluid requires either larger, heavier lines or higher pump power. These considerations more than offset the marginally smaller radiator that results from enhanced heat transfer in the interloop heat exchanger. Based on the result of the detailed analysis, we conclude that nanofluids are not a benefit in spacecraft internal fluid loops.

\section{Nanofluid Use in the External System}

The main reason that nanofluids do not offer an advantage when used in the internal ATCS is that they only marginally improve the interloop heat exchanger performance. Most of the temperature drop in the heat exchanger

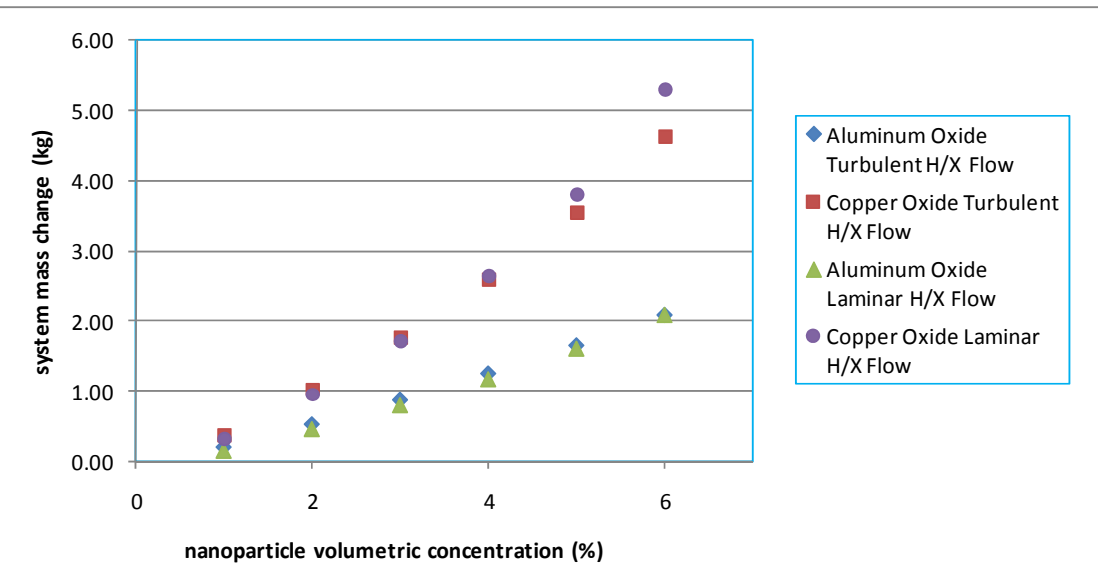

Figure 6. Overall Change in ATCS Mass - Constant Pump Power

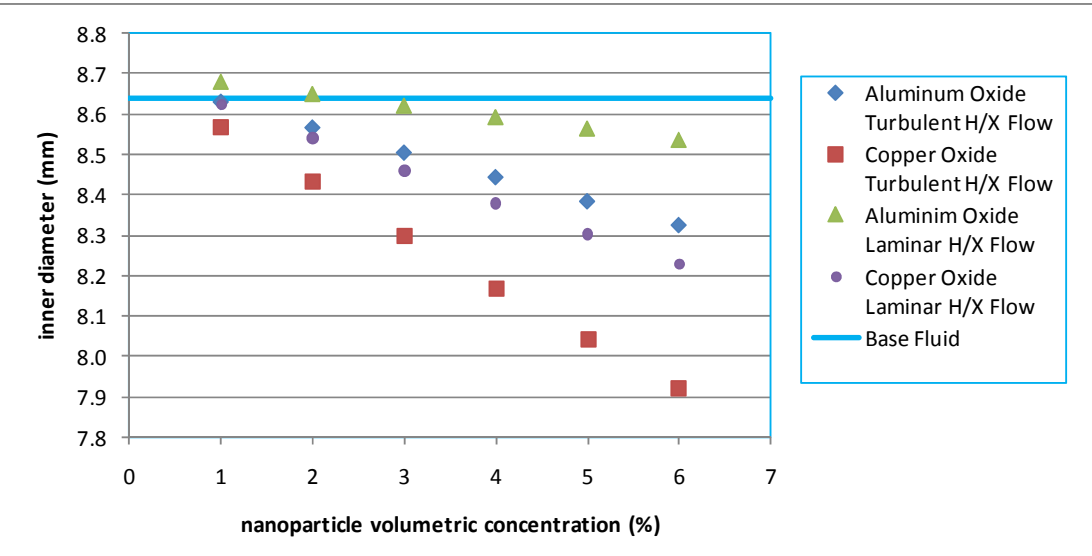

Figure 7. Tube Inner Diameter - Constant System Mass

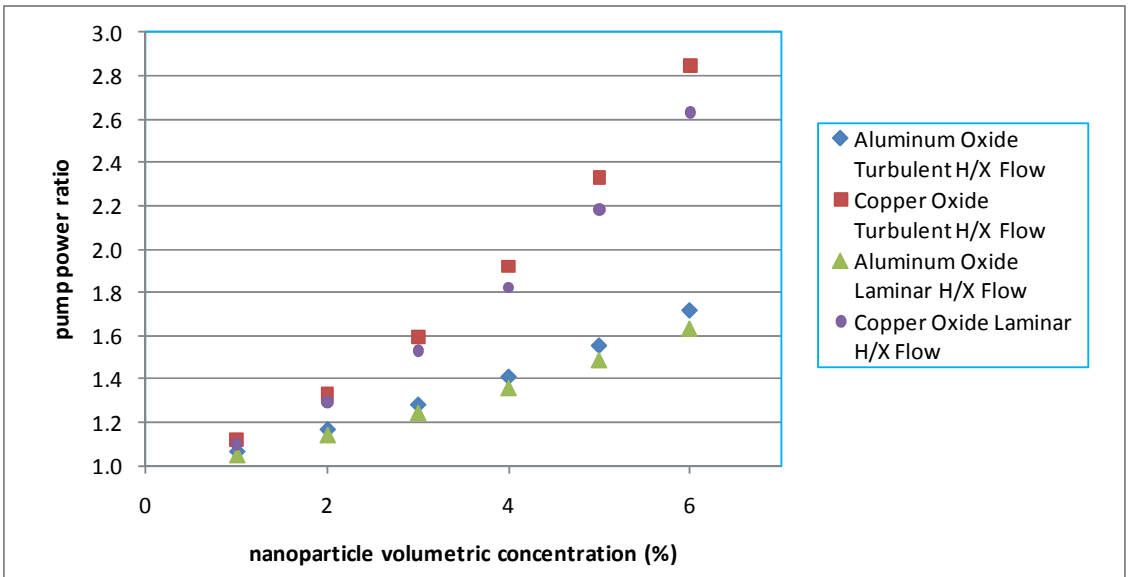

Figure 8. Pump Power Ratio - Constant System Mass 
is on the external fluid side. If nanoparticles were added to the external loop of a spacecraft ATCS, they could have a greater effect on the interloop heat exchanger performance and resulting radiator area. The potentially larger radiator mass savings might lead to an overall system benefit.

Because there is no thermophysical property data for nanofluids based on HFE 7000, we cannot perform an endto-end study to assess this case. However, the results of the internal loop nanofluids study provide a means to predict the likely end-to-end results.

The maximum possible improvement that might occur in the case where nanofluids did improve the interloop heat exchanger performance can be bounded. If the heat transfer coefficient on the HFE 7000 side increased by $50 \%{ }^{\dagger \dagger}$ with the addition of nanoparticles, the overall heat exchanger temperature drop would decrease from 3.9 to $2.8 \mathrm{~K}\left(7\right.$ to $\left.5.1^{\circ} \mathrm{F}\right)$. This would shrink the radiator mass by $2.6 \%$, saving $2.0 \mathrm{~kg}(4.4 \mathrm{lbm})$. This small mass savings would be at least partially offset by the larger fluid lines (for a constant pump power system) or the higher pumping power of a constant mass system.

A property database for HFE 7000/nanoparticle mixtures would be required to provide a definitive assessment. However, given the low upper limit of the radiator mass savings, it appears that the addition of nanoparticles to the external loop is unlikely to result in a significant overall system benefit.

\section{Conclusions}

The effect of using nanofluids in a spacecraft active thermal control system was assessed from a system level perspective. A detailed analysis based on the Orion thermal system specifications, requirements, and component performance showed that the addition of nanofluids to the internal fluid loop does not result in mass or power benefits. In fact, the addition of nanoparticles to the internal fluid loop results in a system that is heavier or uses more pump power than the baseline system. The intermediate results obtained in the study also suggest that that the addition of nanoparticles to the external loop would not be likely to result in a significant overall system benefit.

\section{References}

${ }^{1}$ Das, D. K., Vajjha, R. S., Strandberg, R., and, Kulkarni, D. P., "Enhancement of the Performance of Thermal Control Systems Using Nanofluids," Thermal \& Fluids Analysis Workshop - TFAWS 2010.

2“Ungar, E. K., "Spacecraft Radiator Freeze Protection Using a Regenerative Heat Exchanger with Bypass Setpoint Temperature Control Algorithm," E. K. Ungar, presented at the 38rd International Conference on Environmental Systems, 2008, SAE Paper 2008012170.

${ }^{3}$ Vajjha, R. S. Das, D. K. Kulkarni, D. P, "Development of New Correlations for Convective Heat Transfer and Friction Factor in Turbulent Regime for Nanofluids," International Journal of Heat and Mass Transfer, Vol. 53, Issue s21-22, October 2010, pp. 4607-4618.

${ }^{4}$ Vajjha, R. S., Das, D. K., Namburu, P. K., "Numerical Study of Fluid Dynamic and Heat Transfer Performance of A12O3 and $\mathrm{CuO}$ Nanofluids in Flat Tubes of a Radiator", International Journal of Heat and Fluid Flow, Vol. 31, Issue 4, August 2010, pp. 613-621.

${ }^{5}$ Kays, W. M., and London, A. L., Compact Heat Exchangers. 3rd ed. McGraw-Hill, New York: 1984.

† This is twice the maximum of $27 \%$ found in the present study for the internal loop. 